\title{
Exploiting the Campylobacter jejuni protein glycosylation system for glycoengineering vaccines and diagnostic tools directed against brucellosis
}

\author{
Jeremy A Iwashkiw ${ }^{1}$, Messele A Fentabil ${ }^{2}$, Amirreza Faridmoayer ${ }^{1,6}$, Dominic C Mills ${ }^{1,5}$, Mark Peppler ${ }^{3}$, \\ Cecilia Czibener ${ }^{4}$, Andres E Ciocchini ${ }^{4}$, Diego J Comerci ${ }^{4}$, Juan E Ugalde ${ }^{4}$ and Mario F Feldman ${ }^{1,7^{*}}$
}

\begin{abstract}
Background: Immune responses directed towards surface polysaccharides conjugated to proteins are effective in preventing colonization and infection of bacterial pathogens. Presently, the production of these conjugate vaccines requires intricate synthetic chemistry for obtaining, activating, and attaching the polysaccharides to protein carriers. Glycoproteins generated by engineering bacterial glycosylation machineries have been proposed to be a viable alternative to traditional conjugation methods.

Results: In this work we expressed the C. jejuni oligosaccharyltansferase (OTase) PglB, responsible for $N$-linked protein glycosylation together with a suitable acceptor protein (AcrA) in Yersinia enterocolitica O9 cells. MS analysis of the acceptor protein demonstrated the transfer of a polymer of $\mathrm{N}$-formylperosamine to AcrA in vivo. Because $\mathrm{Y}$. enterocolitica $\mathrm{O} 9$ and Brucella abortus share an identical O polysaccharide structure, we explored the application of the resulting glycoprotein in vaccinology and diagnostics of brucellosis, one of the most common zoonotic diseases with over half a million new cases annually. Injection of the glycoprotein into mice generated an IgG response that recognized the $O$ antigen of Brucella, although this response was not protective against a challenge with a virulent B. abortus strain. The recombinant glycoprotein coated onto magnetic beads was efficient in differentiating between naïve and infected bovine sera.
\end{abstract}

Conclusion: Bacterial engineered glycoproteins show promising applications for the development on an array of diagnostics and immunoprotective opportunities in the future.

Keywords: Brucellosis diagnostics, glycoengineering, Yersinia enterocolitica O9, N-linked protein glycosylation

\section{Background}

Brucella sp., the causative agents of brucellosis, are Gram-negative, facultative intracellular $\alpha$-proteobacteria [1-3]. Three Brucella species, B. abortus, B. melitensis, and $B$. suis are the common species that cause human brucellosis. They can also infect domestic livestock, causing miscarriages and sterility leading to significant economic loss $[4,5]$. Brucellosis is the most common bacterial zoonosis with over half a million new cases

\footnotetext{
* Correspondence: mfeldman@ualberta.ca

'Alberta Glycomics Centre, Department of Biological Sciences, University of Alberta, Edmonton, AB, TG6 2E9, Canada

Full list of author information is available at the end of the article
}

annually and high levels of abortions in cattle in developing countries [6,7]. In addition, Brucella sp. are considered highly effective biological weapons [1]. $B$. abortus is the causative agent for brucellosis in cattle and the second most common cause of human infections [8]. The current commercially available vaccines against $B$. abortus are attenuated strains, which are effective in livestock, but retain virulence to humans [9]. Due to this and other disadvantages, such as the impossibility to discriminate between infected and vaccinated animals during immune-screening procedures, new vaccines against brucellosis are required. Among several promising vaccine candidates is a live attenuated strain 
lacking the phosphoglucomutase gene $(\Delta p g m)$, which is unable to assemble the $\mathrm{O}$ polysaccharide [10].

Immune responses directed towards surface polysaccharides are effective in preventing colonization and infection against several bacterial pathogens [11]. However, to generate long-term protection in children, the polysaccharides must be covalently attached to an appropriate protein carrier [11,12]. The efficacy of conjugating bacterial polysaccharides to proteins is best exemplified by the Haemophilus influenzae type b conjugate vaccine, which has virtually eradicated the infections caused by this organism in most parts of the world [11]. Indeed, glycoconjugate vaccines have also been used for the prevention and treatment of a diverse array of bacterial, viral, protozoan, parasitic, and cancerous diseases [11]. Presently, the production of these conjugate vaccines requires intricate synthetic chemistry for obtaining, activating, and attaching the polysaccharides to protein carriers [11]. The polysaccharides are either obtained from the target pathogen, or by laborious synthesis. Extraction of the polysaccharides from pathogenic organisms usually requires large cultures, which constitutes a major health hazard [13]. Furthermore, when purifying $\mathrm{O}$ antigens, chemical removal of the endotoxin is required to prevent fever [11]. In most cases, bacterial polysaccharides are too complex to be synthesized efficiently by chemical methods, which make this process economically unfavorable [13]. In the final stage of conjugation, chemical attachment of the carbohydrate to the protein often results in large and heterogeneous conjugates. In addition, a considerable amount of toxic waste is generated during the conjugation process [13]. For these reasons, production of conjugate vaccines using conventional procedures is complex and the costs are prohibitive for global vaccination programs.

The $\mathrm{O}$ antigen of $B$. abortus and B. suis is a homopolymer of $\mathrm{N}$-formylperosamine $[14,15]$. Only a few studies evaluating the suitability of conjugate vaccines against Brucella have been published. A conjugate vaccine obtained by covalently coupling the $\mathrm{O}$-polysaccharide obtained from $B$. melitensis to bovine serum albumin (BSA) induced antibodies and was protective in mice [16]. Nevertheless, because Brucella sp. requires class III biosafety facilities, production of glycoconjugates containing Brucella glycans in its native host is challenging and possibly unsafe. It has recently been established that conjugates containing polysaccharide from pathogenic bacteria can be produced in E. coli by exploitation of bacterial glycosylation systems. Bacterial oligosaccharyltransferases (OTases) are enzymes capable of transferring glycan chains, including polysaccharides, from lipid carriers to proteins, in a process called en bloc protein glycosylation [17]. OTases involved in both,
$N$ - and $O$-glycosylation have been characterized in bacteria $[17,18]$. The most thoroughly studied bacterial glycosylation system is the $N$-glycosylation machinery of Campylobacter jejuni [17,19-21]. N-glycosylation is initiated by a specialized glycosyltransferase that attaches a nucleotide-activated monosaccharide-1P to an undecaprenolphosphate (Und-P) lipid carrier on the inner face of the inner membrane. A series of glycosyltransferases subsequently attach additional monosaccharides to the first sugar residue on Und-PP. When the carbohydrate structure is completed, the Und-PP linked glycan is flipped to the periplasmic face, where the $N$-OTase PglB transfers the carbohydrate to protein acceptors with a consensus sequence of $\mathrm{D} / \mathrm{E}-\mathrm{Y}-\mathrm{N}-\mathrm{X}-\mathrm{S} / \mathrm{T}(\mathrm{Y}, \mathrm{X} \neq \mathrm{P})$ $[22,23]$. Previous work has demonstrated that $C$. jejuni PglB can transfer an array of glycans, including O-antigens, from the lipid donors to carrier proteins [21]. Due to their versatility, bacterial glycosylation systems can be seen as toolboxes for engineering novel glycoconjugates. Conjugates produced by this method may constitute a new generation of vaccines, circumventing most of the disadvantages of the conventional chemical methods, significantly reducing costs, and improving the reproducibility of the product obtained. In this work, we exploited the $C$. jejuni $\mathrm{N}$-glycosylation machinery to engineer $N$-linked glycoproteins and tested their possible applications in vaccinology. We also demonstrated that these glycoproteins have promising applications for the diagnosis of brucellosis.

\section{Results}

Cross reactivity between Brucella and $Y$. enterocolitica 0:9

The $B$. abortus and $B$. suis $\mathrm{O}$ antigens were previously characterized by genomic analysis, NMR, and serological assays and appear to be identical to that of Yersinia enterocolitica O:9 (Ye O:9) [15,24,25]. Ye O:9 is a Class II biosafety hazard organism and is easily manipulated and cultured, making it a suitable host for the production of the glycoconjugate protein with the $\mathrm{N}$-formylperosamine homopolymer, which we hypothesize could cross-protect against brucellosis [26]. In some $Y$. enterocolitica strains, an additional "outer core" (OC) consisting of a shorter glycan chain is assembled onto the Und-PP carrier and subsequently ligated to lipid A. To confirm cross reactivity of the Ye O:9 (Table 1) and the $B$. abortus $\mathrm{O}$ antigens, LPS of both species were analyzed by SDS-PAGE and immunoblot (Figure 1). Our analysis included the wild-type Ye O:9 strain, plus three derivatives lacking the $\mathrm{OC}$, the $\mathrm{O}$ antigen, or both glycan structures. LPS samples from of the Ye O:9 strains exhibited a different electrophoretic pattern according to the mutation carried by each strain. The double mutant strain only displayed a band corresponding to lipid A core (lane 1). The $\mathrm{O}$ antigen deficient strain 
Table 1 Strains and Plasmids used in this study

\begin{tabular}{|c|c|c|}
\hline Strain/Plasmid & Description & Source \\
\hline PMAF10 & HA-tagged $\mathrm{Pg}_{\mathrm{I}} \mathrm{B}_{\mathrm{Cj}}$ cloned in pMLBAD, $\mathrm{Tmp}^{\mathrm{R}}$ & $(11)$ \\
\hline pMH5 & Soluble periplasmic hexa-His-tagged AcrA under control of Tet promoter, in PACYC, $\mathrm{Cm}^{\mathrm{R}}$ & (11) \\
\hline YeO9-c-OC (OC-) & $\Delta(w z x-w b c L):: K m G B ; O C$ negative; derivative of Ruokola/71-c & (35) \\
\hline YeO9-OC-R (OC-/HP-) & Phage ØR1-37-resistant spontaneous OC-negative derivative of YeO9-R1 & (35) \\
\hline YeO9-R1 (HP-) & $\Delta$ per::KmGB; rough (O-antigen negative); $\mathrm{Km}^{\mathrm{r}}$ derivative of Ruokola/71 & $(32,35)$ \\
\hline$\overline{R u o k o l a / 71-c ~(W T) ~}$ & Spontaneous virulence plasmid-cured derivative of Ruokola/71 & (32) \\
\hline
\end{tabular}

exhibited a unique band that migrated slower than the lipid A core, as expected for the presence of the low molecular weight OC structure attached to the lipid A (lane 2). The OC minus strain only produced the high molecular weight homopolymer (lane 3), and the WT strain produced both glycan structures (lane 4; Figure 1A). Analysis of the LPS extracts using monoclonal antibodies (Figure 1B, C) demonstrated that only the high molecular weight carbohydrate of Ye O:9 was reactive towards the Yst9-2 (anti-Ye O:9 antigen) monoclonal antibody (mAb; Figure 1B, lanes 3 and 4). The Yst9-2 $\mathrm{mAb}$ antibody also recognized the $\mathrm{O}$ antigen of $B$ abortus, B. melitensis and B. suis, confirming the cross reactivity of the LPS between the species (Figure 1B, Lanes 5-7). The M84 mAb directed against B. abortus $\mathrm{O}$ antigen also reacted with the Ye O:9 polysaccharide (Figure 1C, lanes 3 and 4). Interestingly, B. melitensis LPS did not react towards the M84 antibody (Figure 1C, lane 6). This result was not totally unexpected because although the $B$. abortus and B. melitensis polysaccharides have a similar composition, there are structural differences between their $\mathrm{O}$ antigens [27]. These results confirmed that the $\mathrm{O}$ antigens of Ye 0:9 and B. abortus have a similar structure, and suggested that a conjugate carrying the Ye O:9 antigen could mount an immune response that may be cross-protective against B. abortus.

\section{Purification of glycosylated AcrA from Y. enterocolitica $0: 9$ strains}

In earlier work, $\mathrm{N}$-glycosylated AcrA was synthesized in E. coli by co-expression of C. jejuni PglB and AcrA with an appropriate carbohydrate structure [22]. In order to determine if we could transfer the Ye 0:9 carbohydrate structures to AcrA in Ye O:9, we transformed each of the strains with pMAF10, expressing PglB under an arabinose-inducible promoter, and pMH5, expressing a 6His-tagged version of AcrA. Cultures of each transformed strain were grown and induced as required, and AcrA was purified from periplasmic extracts by affinity chromatography and analyzed by SDS-PAGE (Figure 2). The single band visualized by Coomassie stain (Figure 2A) suggested that AcrA was unglycosylated in the double mutant strain (lane 1), while the two glycosylation sites of AcrA were modified with $\mathrm{OC}$ in the $\mathrm{O}$ antigen mutant strain producing an additional two bands (lane 2 ). The large molecular weight $O$ antigen was transferred to AcrA in the OC mutant strain (lane 3, and $3^{*}$ ), and both glycan structures were bound to AcrA in the Ye O:9 WT (lane 4). Additionally, the purified AcrA samples were analyzed by immunoblot using $\alpha$-AcrA antibodies (Figure 2B). The different pattern observed in each sample confirmed that different glycans were attached in each strain. Interestingly, unglycosylated AcrA appeared as a double band (lane 1). The OC mutant strain displayed a pattern compatible with a poorly glycosylated form of AcrA with the $\mathrm{O}$ antigen (Figure $2 \mathrm{~A}$ and $2 \mathrm{~B}$, lanes 3 and $3 *$ ). These conclusions were further supported by a immunoblot of the same samples using the $\alpha$-Yersinia O:9 (Yst9-2) and the $\alpha$ Brucella $\mathrm{O}$ antigen (M84) monoclonal antibodies (Figure $2 \mathrm{C}$ and 2D, respectively). These results indicated the $C$. jejuni glycosylation system was efficiently reconstituted in $Y$. enterocolitica O:9. Although the OC- mutant would be the ideal strain for the generation of the conjugate carrying the O:9 antigen, the unexpectedly low AcrA glycosylation levels in this strain prevented its utilization for the production of the conjugate. For this reason, the conjugate containing the Ye O:9 antigen was purified from the wild-type strain.

\section{Identification of the carbohydrates attached to AcrA by mass spectrometry}

In order to fully characterize the carbohydrates attached to AcrA, mass spectrometry techniques were employed. AcrA was purified from Ye O9 strains, separated by SDS-PAGE, the bands of interest were excised and ingel digested with trypsin, and the resulting peptides analyzed by ESI-Q-TOF MS and MS/MS. Examination of the higher molecular weight smear from the Ye O:9 WT glycosylated AcrA by MS revealed a peak at $1954.7^{1+}$ $\mathrm{M} / \mathrm{Z}$, and subsequent analysis of this peak by MS/MS identified the known glycopeptide DFNR modified with a carbohydrate moiety (Figure 3A). We identified a HexNAc-Hex disaccharide followed by a $173 \mathrm{M} / \mathrm{Z}$ repeat, which corresponds to the $\mathrm{N}$-formylperosamine homopolymer, attached to the tetrapeptide DFNR, which 
between the two different genus' LPS is observed by both monoclonal antibodies reacting against the higher molecular weight homopolymeric $\mathrm{N}$-formylperosamine polysaccharide.

represents one of the known glycosylation sites of AcrA (Figure 3A). MS analysis of the glycoprotein produced by $\mathrm{O}$ antigen deficient strain revealed a peak of $1284.6^{3+}$ $\mathrm{M} / \mathrm{Z}$. MS/MS analysis of this peak identified the second known glycosylated site of AcrA (AVFDNNNSTLLPGAFATITSEGFIQK) modified with the hexasaccharide HexNAc-HexNAc-Hex-Hex-HexNAc-Hex (Figure 3B). This hexasaccharide is known as the outer core and is also present in $Y$. enterocolitica O:3. Contrary to previously published work, the outer core of Ye O:9 is therefore not structurally homologous to that of $Y$. enterocolitica O:3, despite genetic homology [28,29].

\section{a-Yersinia}
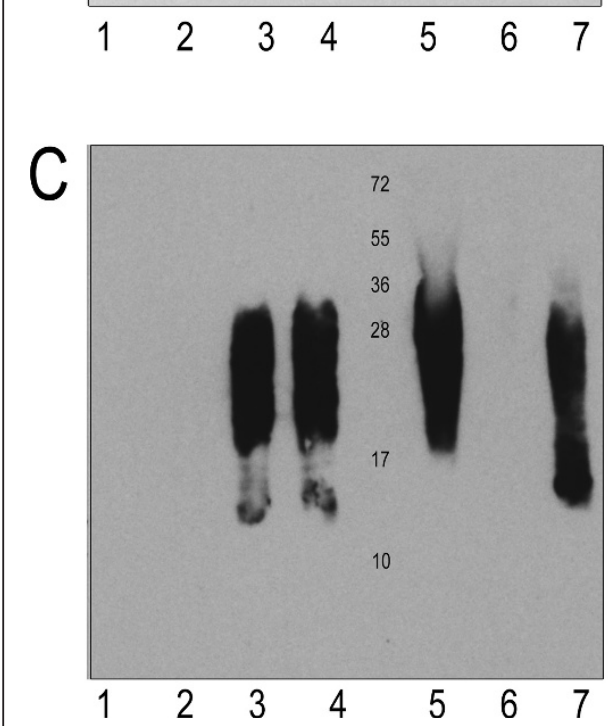

a-Brucella

Figure 1 Cross reactivity between $Y$. enterocolitica 0:9 and Brucella spp. LPS samples. (0.2 OD/sample loaded) on 15\% SDSPAGE: A) LPS silver stain analysis of samples of $Y$. enterocolitica 1) OC-/HP-, 2)HP-, 3) OC-, 4) WT; Brucella 5) B. abortus, 6) B. melintensis, and 7) B. suis. B) Immunoblot against the same samples with monoclonal $\alpha$-Yersinia (Yst 9-2). C) Immunoblot of the same samples using monoclonal $\alpha$-Brucella (M84). Cross reactivity
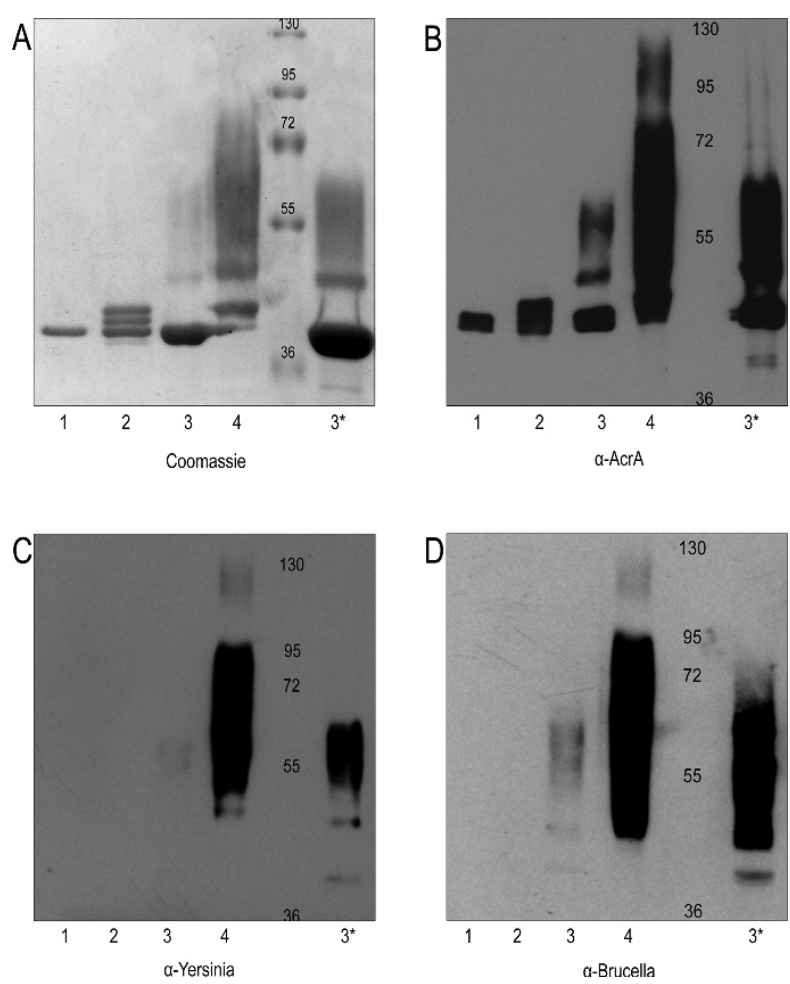

Figure 2 Proteins carrying $Y$. enterocolitica 0:9 0 -antigens are immunoreactive against $\alpha$-Yersinia and $\alpha$-Brucella monoclonal antibodies. Each strain was transformed with pMAF10 (pg/B $\left.B_{\mathrm{Cj}}\right)$ and pMH5 (acrA), and glycosylated AcrA was purified from $1 \mathrm{~L}$ of culture using $\mathrm{Ni}^{2+}$ affinity chromatography. After purification, samples were loaded onto a 10\% SDS-PAGE gel and analyzed by: A) Coomassie brilliant blue ( $5 \mu \mathrm{g} / \mathrm{sample}$ ), immunoblot (2 $\mu \mathrm{g} / \mathrm{sample})$ using B) $\alpha$ AcrA, C) $\alpha$-Ye O:9 (Yst9-2) mAb, or D) $\alpha$-Brucella $\mathrm{O}$ antigen M84 mAb. Samples were purified from the following strains: 1) OC-/HP-, 2) $\left.\mathrm{HP}_{-}, 3\right) \mathrm{OC}-$, 4) WT, and $\left.3^{*}\right) 10 \times$ loaded volume of $3(\mathrm{OC}-$ ). 

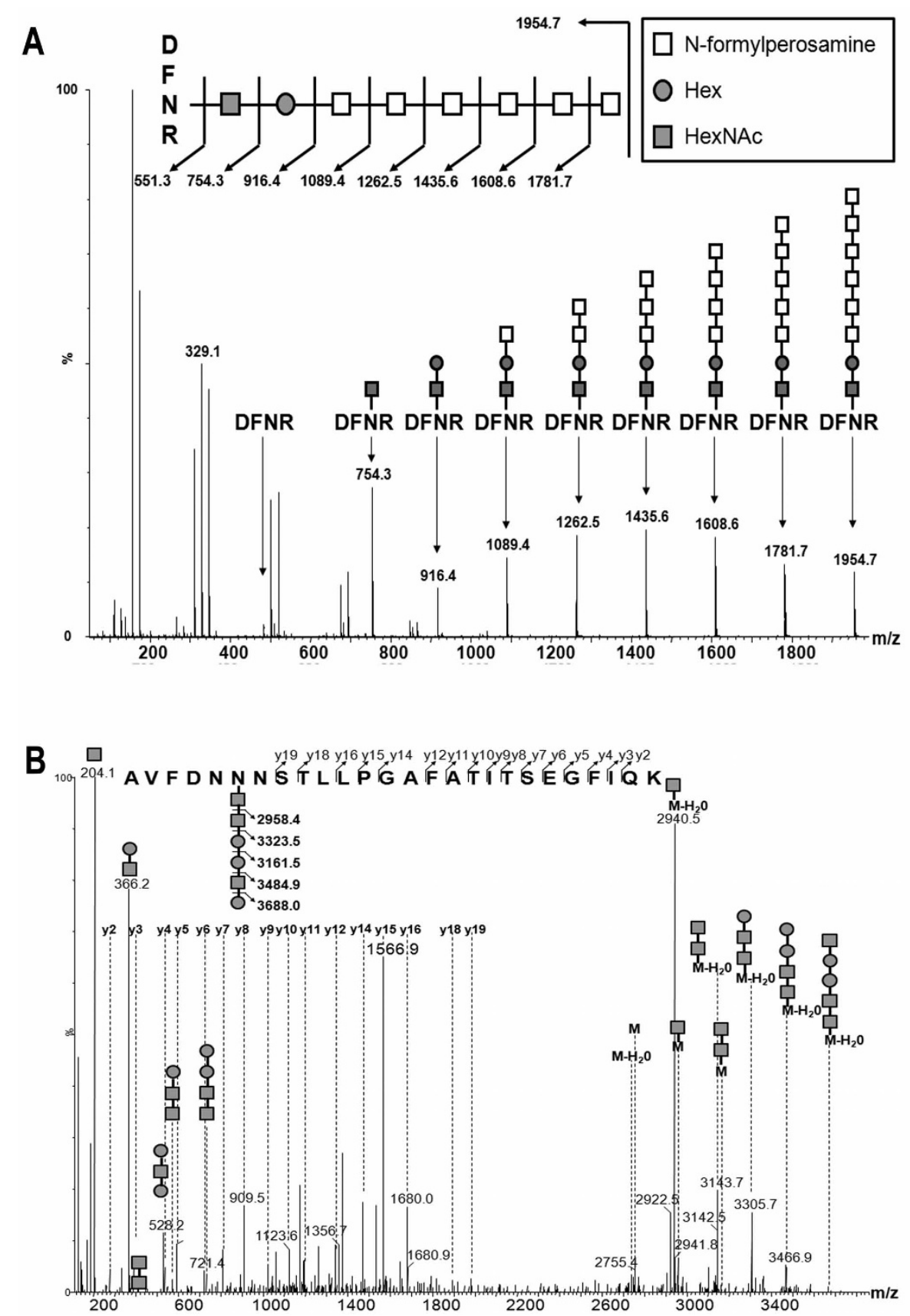

Figure 3 ESI-Q-TOF MS and MS/MS analysis of of $Y$. enterocolitica 0:9 glycobioconjugates. A) MS of high molecular weight glycosylated AcrA purified from Ye O:9 WT revealed the peak 1954.7 M/Z. MS/MS of this peak showed a disaccharide of HexNAc-Hex linking a characteristic $173 \mathrm{M} / \mathrm{Z}$ pattern corresponding to the N-formylperosamine subunit to the known glycopeptide DFNR. B) MS of high molecular weight glycosylated AcrA purified from Ye 0:9 O antigen mutant revealed the peak $1284.6^{3+} \mathrm{M} / \mathrm{Z}$. MS/MS of this peak shows the second known glycosylated site of AcrA (AVFDNNNSTLLPGAFATITSEGFIQK) modified with the hexasaccharide HexNAc-HexNAc-Hex-Hex-HexNAc-Hex.

Immune Response in BALB/c Mice vaccinated with O9-glycosylated AcrA

To evaluate the potential use of the glycoprotein as conjugate vaccine, the purified AcrA containing the Ye O:9 antigen was injected intraperitoneally into mice to measure the immune response as well as test subsequent protection against a challenge with $B$. abortus. The concentration of purified glycosylated AcrA was quantified as $1.77 \mathrm{mg} / \mathrm{mL}$ for protein and $0.71 \mathrm{mg} / \mathrm{mL}$ for carbohydrate, giving a protein: carbohydrate ratio of 2.48 . Three separate groups of mice were injected, one with unglycosylated AcrA and two with different amounts $(1.5 \mu \mathrm{g}$ 
and $3 \mu \mathrm{g}$ of carbohydrate per mouse) of glycosylated AcrA, respectively. After a second injection of glycoprotein, sera obtained from the control (Figure 4A, C, and $4 \mathrm{E}$ ) and $3 \mu \mathrm{g}$ group (Figure $4 \mathrm{~B}, \mathrm{D}$, and $4 \mathrm{~F}$ ) were analyzed for IgG immune response by immunoblot. As expected, both sets of sera reacted strongly against AcrA (Figure 4A, b). However, when the sera were
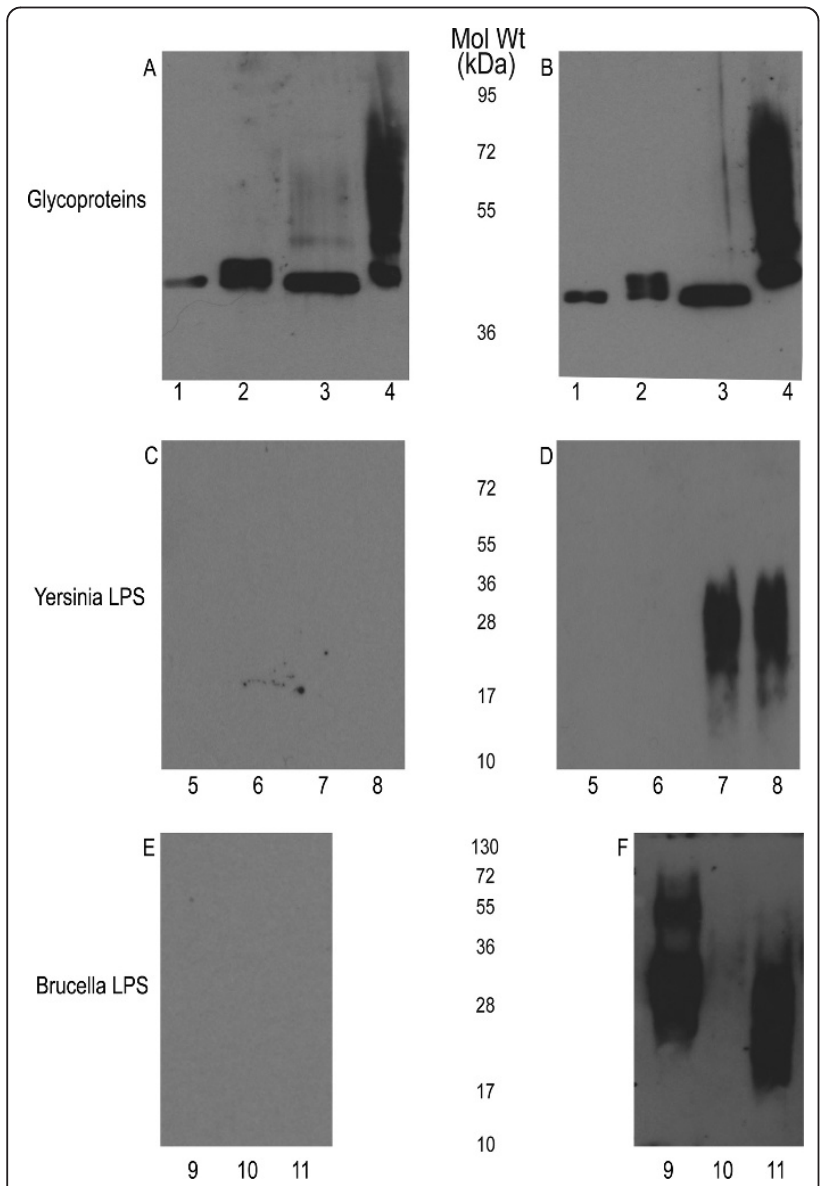

Figure 4 Sera of BALB/c mice immunized with bioconjugate shows a directed IgG immune response against $\mathrm{N}$ formylperosamine of $Y$. enterocolitica 0:9 and Brucella spp. A) Control sera and $\mathbf{B}$ ) Immune sera raised by injecting purified glycoproteins containing $3 \mu \mathrm{g}$ glycan: 1) Unglycosylated AcrA, 2) HP-, 3) OC-, 4) WT. Both sets of sera react with each glycoprotein due to the high immunostimulatory characteristic of AcrA. C) Control sera and D); immune serum (IgG response) blotted against $Y$. enterocolitica 0:9 LPS from different strains from Figure 1. 5) OC-/ HP-, 6) HP-, 7) OC-, 8) WT. Only the test serum was reactive against the higher molecular weight portion corresponding to the homopolymer of $\mathrm{N}$-formylperosamine. $\mathbf{E})$ Control sera and $\mathbf{F}$ ) immune serum blotted against Brucella spp. LPSs: 9) B. abortus, 10) $B$. melitensis, and 11) B. suis. Only the immune sera are reactive against the Brucella LPS. Interestingly, although each LPS is comprised of $\mathrm{N}$-formylperosamine, different linkages are present which may cause the difference in reactivity of the sera. assayed against the purified $Y$. enterocolitica LPS, only the groups injected with glycosylated AcrA were reactive against purified LPS samples from $Y$. enterocolitica O:9 OC mutant and WT strains, indicating that IgG antibodies against the $\mathrm{N}$-formylperosamine homopolymer were generated (Figure $4 \mathrm{C}, \mathrm{D})$. No reactivity was observed for the control sera towards the Brucella LPS, whereas the sera from the mice injected with glycosylated AcrA showed a strong immunoreactivity towards the $B$. abortus and B. suis LPS (Figure 4E, F). A very weak response was observed against the $B$. melintensis LPS.

The generation of antibodies against the Ye O:9 antigen was further analyzed by ELISA. Each well was coated with $12.5 \mu \mathrm{g}$ of Ye O:9 LPS (Figure 5). Of the three groups of mice, only the sera from mice belonging to the two groups inoculated with glycosylated AcrA showed an IgG response directed towards the polysaccharide. However, a high level of variation in the absorbance values was observed, with some animals showing no significant response. Interestingly, the group of mice inoculated with the lower amount of glycoprotein $(1.5 \mu \mathrm{g})$ exhibited a higher average $\mathrm{OD}_{405} \mathrm{~nm}$ than the group inoculated with $3 \mu \mathrm{g}$. Nevertheless, the immune response was insufficient or inefficient in protecting the mice against a challenge with $B$. abortus, as no statistical difference was observed in bacterial load in the spleen of infected mice irrespective of whether they were injected with glycosylated or unglycosylated AcrA (data not shown).

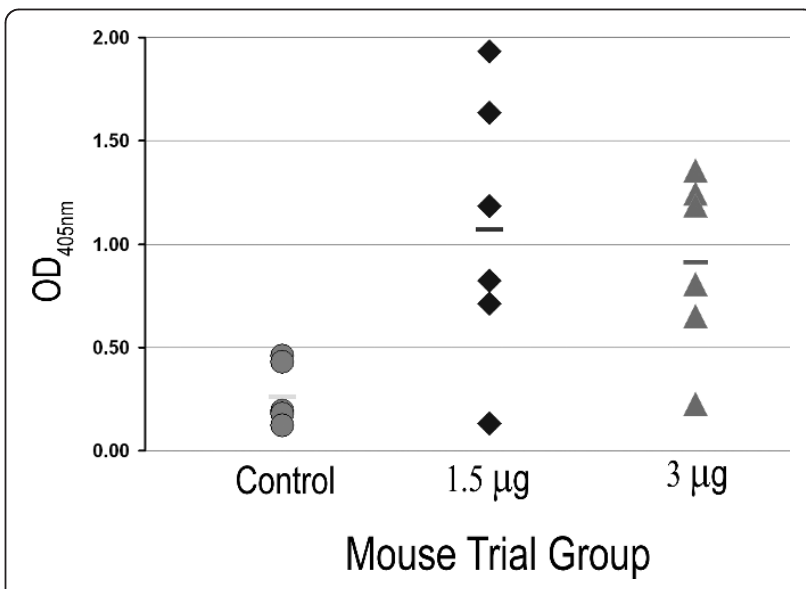

Figure 5 BALB/c mice elicit an IgG immune response against $Y$. enterocolitica LPS, but is not protective against $B$. abortus infection. A) ELISA response of the sera obtained from the third bleed (1/200 dilution) of the different mouse groups against $Y$. enterocolitica 0:9 LPS. Microtiter plates were coated with $12.5 \mu \mathrm{g}$ of Y. enterocolitica 0:9 LPS. Each datum point represents the average of three replicate wells. Response was read after $1 \mathrm{~h} @ 37^{\circ} \mathrm{C}$ at $\mathrm{OD}_{405} \mathrm{~nm}$. The bar in each set of data corresponds to the average of each group. 


\section{Glycoconjugates as novel antigens for the diagnosis of brucellosis}

Because vaccination with the glycosylated AcrA induced the production of a specific IgG immune response against the $\mathrm{O}$-antigen, we asked if this glycoconjugate could be used as an antigen for the diagnosis of the infection in cows. To test this, we immobilized AcrA (control) or AcrA-O:9 on paramagnetic microbeads (see Materials and Methods) and tested the reactivity towards sera from non-infected animals, as well as from cows vaccinated with the B. abortus $\Delta p g m$ or infected with B. abortus 2308 strain. These animals are part of an efficacy trial to test the protective capacity of the $\Delta p g m$ strain $[10,30]$ (manuscript in preparation). As mentioned earlier, $\Delta p g m$ is a rough strain that does not induce the production of anti-O-antigen specific immunoglobulin titers in mice. As can be observed in Figure 6A, the assay clearly differentiates non-infected from infected animals and does not react with sera from animals vaccinated with a strain that lacks a complete LPS. Additionally, it is shown that none of these sera reacted against the non-glycosylated form of AcrA in a immunoblot indicating that the IgG response detected is directed specifically towards the carbohydrate moiety of the antigen (Figure 6B). Taken together, these results strongly suggest that this novel antigen could be used for the development of new diagnostic tools for brucellosis.

\section{Discussion}

Because the $Y$. enterocolitica O:9 and B. abortus LPSs share the same structure, we hypothesized that a glycoprotein carrying the Ye O:9 glycan would be able to generate antibodies recognizing $B$. abortus $\mathrm{O}$ polysaccharide, with the overall goal of eliciting a protective

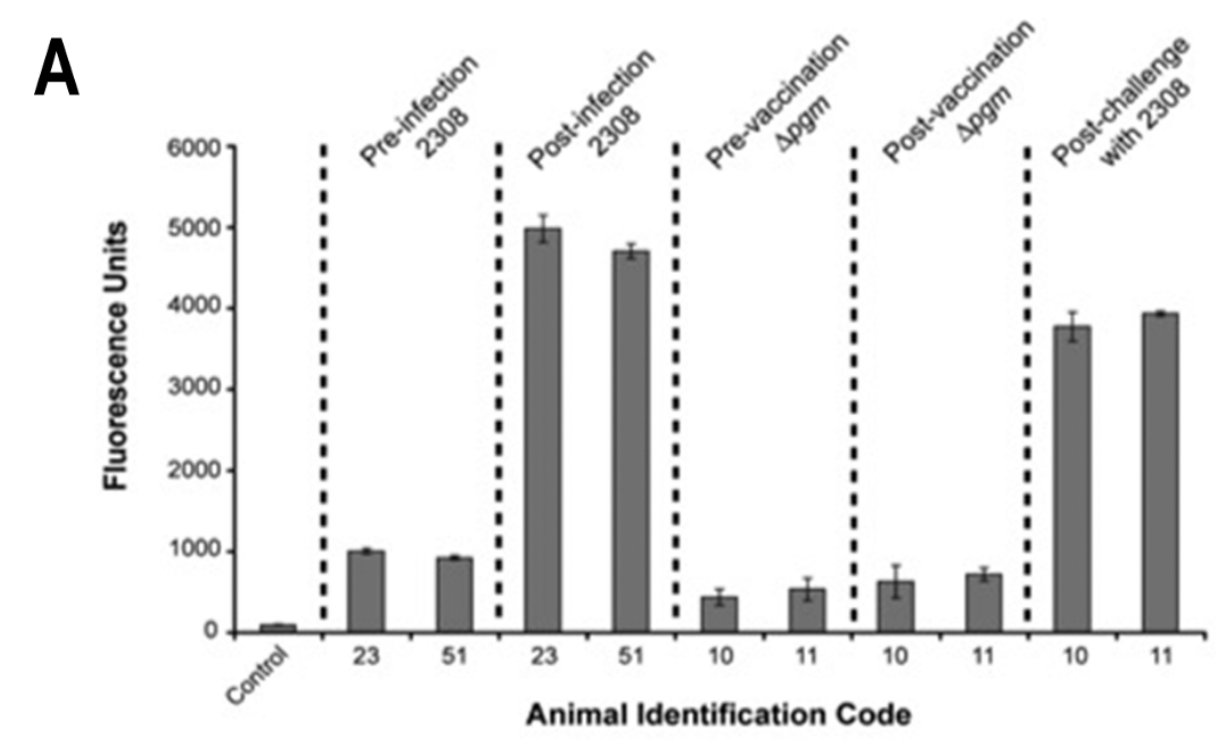

B

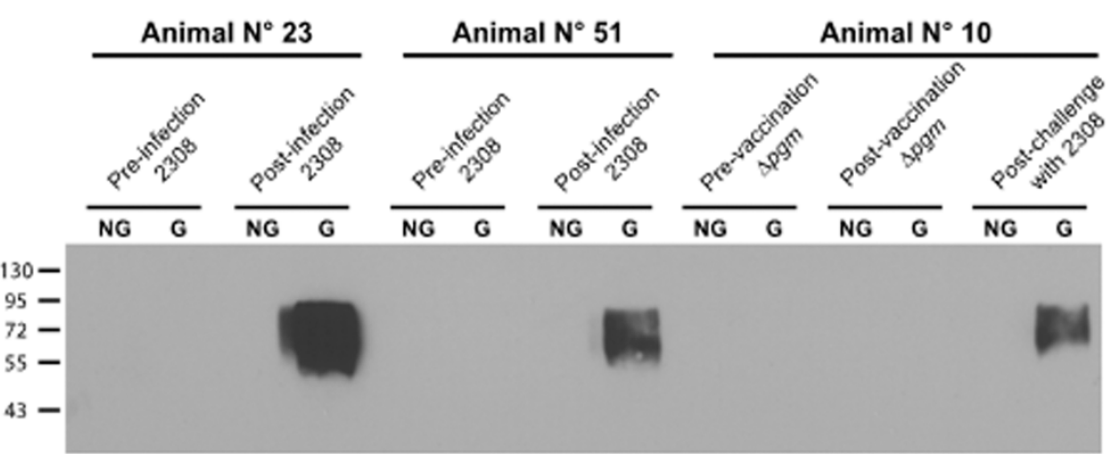

Figure 6 Y. enterocolitica 0:9 bioconjugate as a promising antigen for the diagnosis of bovine brucellosis. A) Magnetic bead-based immunoassay for detection of antibodies against Brucella abortus O-antigen. Magnetic beads coated with the AcrA-OAg glycoconjugate were incubated with the indicated bovine serum samples (dilution 1/200). Bound antibodies were detected using a Cy5-conjugated goat anti-bovine IgG. The bar graph data represents the means and standard deviation for two separate determinations. Control: magnetic beads incubated with PBS-Tween $0.1 \%$. B) Immunoblot of the same bovine serum samples. 
immune response against infection by this organism. We also explored if such a glycoprotein could be used for the diagnosis of brucellosis. We confirmed, using immunoblot, that $\mathrm{mAb}$ raised against Yersinia O:9 and $B$. abortus $\mathrm{O}$ antigens can cross-react with both structures. A glycoprotein consisting of the $Y$. enterocolitica $\mathrm{O}: 9$ antigen attached to the carrier protein AcrA was obtained in vivo by expression of the $N$-linked protein glycosylation OTase PglB of C. jejuni in Y. enterocolitica strains. The glycoprotein was purified from Ye O:9 cells and characterized by MS techniques. We confirmed the attachment of a polymer of $\mathrm{N}$-formylperosamine to AcrA, which was reactive towards two mAbs directed against Ye $\mathrm{O}: 9$ and $B$. abortus $\mathrm{O}$ antigens, respectively. However, we also identified a previously unreported disaccharide with the formula HexNAc-Hex acting as a linker between the protein and the Ye O:9 homopolymer. A similar linker has been described in many homopolymeric $\mathrm{O}$ antigens in different bacterial species [31] and also in other polysaccharides such as the arabinogalactan of $M$. tuberculosis and the teichoic acids in Grampositive bacteria ([32]. This indicates that disaccharides acting as linkers are a common feature in the synthesis of bacterial polysaccharides via the polymerase (wzy) independent pathway. Additionally, MS/MS analysis demonstrated the attachment of shorter glycan to AcrA in the wild type strain, with a structure of HexNAcHexNAc-Hex-Hex-HexNAc-Hex. This hexasaccharide is known as the outer core and is also present in $Y$. enterocolitica $\mathrm{O}: 3$. Based on genetic similarities within the $\mathrm{O}: 9$ and the O:3 strains, it was hypothesized that the structures in both strains would be identical. However, our results demonstrate that a different structure is generated in the O:9 strain $[29,33]$.

Injection of AcrA-O9 in mice was able to elicit an IgG immune response against the O:9 polysaccharide. Sera of inoculated mice reacted with Ye O:9 LPS, and $B$. abortus and $B$. suis $\mathrm{O}$ antigens. However, the reaction towards $B$. melitensis $\mathrm{O}$ polysaccharide was practically undetectable. $B$. abortus has both an A ( $\alpha$-1,2-linked homopolymer of $\mathrm{N}$-formyperosamine) and an $\mathrm{M}$ (pentasaccharide with four $\alpha-1,2$ and one $\alpha-1,3$-linked polymers of the same sugar) epitope [14]. Y. enterocolitica $\mathrm{O}: 9$ antigen is comprised solely of $\alpha 1$,2-linked $\mathrm{N}$-formylperosamine, B. abortus has $\sim 98 \%$ A epitope, B. suis has a unique 1:7 ratio of $\alpha 1,3-\alpha 1,2$ linked polymer, whereas $B$. melitensis has only the $\mathrm{M}$ antigen of the pentasaccharide repeat [14]. These structural details help to explain why the M84 mAb against $B$. abortus does not recognize $B$. melitensis LPS, as this mAb is likely directed to an epitope absent in B. melitensis. However, the three Brucella strains reacted against the mAb $\alpha$-Yersinia antibody, reflecting common epitopes that exist in the four structures (Figure 1B). We therefore expected that these common epitopes present in the AcrA-O9 glycoprotein would elicit antibodies that would also cross react with $B$. melitensis LPS, but the sera of the mice injected with AcrA-O9 failed to recognize B. melitensis LPS. This indicates that the common epitopes in all the structures are not the immunodominant ones. Interestingly, although AcrA was glycosylated with both the Ye O:9 and the OC glycan structures, only the O:9 antigen was detected by the mice sera, suggesting that the outer core is not immunogenic (Figure 4D).

A previous report suggested that a conjugate containing BSA and the $\mathrm{O}$ polysaccharide of $B$. melitensis was protective in mice [16]. In preliminary experiments we found that passive immunization with the Yst9 $\mathrm{mAb}$ was protective against $B$. abortus challenge (data not shown). These results prompted us to test the efficacy of our recombinant glycoconjugate against $B$. abortus challenge. An elevated dispersion in the titers of the vaccinated mice was obtained. However, no correlation between antibody titers and bacterial load in the spleen was found, resulting in the absence of difference in bacterial colonization of the three groups. Lack of protection could possibly be explained by the fact that $B$. abortus is an intracellular pathogen and that antibodies against this bacterium may not be able to encounter the microorganism once the infection is established. Alternatively, higher antibody titers may be necessary to elicit a protective immune response. The antibody titers were higher in the animals vaccinated with the lowest amount of glycoconjugate. It is possible that lower amounts of antigen may have to be injected to obtain protective antibody titers.

Our AcrA-O9 conjugate showed promising applications in the diagnostics of brucellosis. Diagnostics of brucellosis using lipopolysaccharide (LPS) as an antigen have been previously explored [34]. LPS are large molecules that also contain a core polysaccharide and a lipid A moiety, as well as the $\mathrm{O}$ antigen. LPS-based assays often suffer from false positives due to the presence of antibodies against common core antigen and lipid A, generated by other bacterial species. Here, we showed that coating magnetic beads with the AcrA-O:9 glycoprotein allows the distinction between infected and uninfected cows. The assay will be particularly useful in conjunction with vaccines like the RB51 or the $\Delta p g m$ strain, which do not have $\mathrm{O}$ antigen, as our assay will allow the distinction between vaccinated and infected animals. Further studies will be carried out to confirm the suitability, i.e. sensitivity and specificity of this assay for detection of bovine and human brucellosis.

Ten years have gone by since the demonstration that bacterial glycosylation systems can be successfully transferred into E. coli. Since then we have learned that the bacterial OTases have a relaxed specificity and are able 
to transfer a variety of glycans, including $\mathrm{O}$ antigens, to suitable protein acceptors. The experiments presented here demonstrate that an IgG immune response can be mounted against the glycan moieties in bacterial glycoproteins. Further work will expand these efforts for the generation of novel vaccines against other important bacterial pathogens. Furthermore, we also expect that the platform presented here for the detection of brucellosis will also be applied in the future for the design of additional bacterial-glycoprotein based diagnostic methods.

\section{Conclusions}

In summary, the C. jejuni $\mathrm{N}$-glycosylation system can be exploited to engineer designer glycoproteins. These glycoproteins can be utilized for carbohydrate characterization, vaccinology, and diagnostics. Mice injected with the YeO9-AcrA glycoconjugate were able to develop immune responses towards different Brucella sp., but protection was not achieved. When magnetic beads were coated with the YeO9-AcrA recombinant glycoprotein, differentiation between naïve and $B$. abortus infected bovine sera was easily discernable. These new biologically engineered glycoconjugates may be developed for a vast array of diagnostic and immunoprotective opportunities in the future.

\section{Materials and methods}

\section{Bacterial strains, plasmids, and growth conditions}

Yersinia enterocolitica O:9 strains were grown in LB media@ $@ 7^{\circ} \mathrm{C}$. Trimethoprim $(100 \mu \mathrm{g} / \mathrm{mL})$ and chloramphenicol $(20 \mu \mathrm{g} / \mathrm{mL})$ were used for plasmid selection as required. The strains and plasmids used in this study are listed in Table 1.

\section{Production and purification of glycosylated AcrA}

Ye O:9 strains transformed with $C$. jejuni PglB (pMAF10) and AcrA (pMH5) were grown overnight at $37^{\circ} \mathrm{C}$. Cultures were reinnoculated $1 / 100$ into fresh $\mathrm{LB}$ media and grown at $37^{\circ} \mathrm{C}$ for $2.5 \mathrm{~h}\left(\mathrm{OD}_{600} \sim 0.5\right)$ and $\mathrm{PglB}_{\mathrm{Cj}}$ expression was induced with addition of arabinose to a final concentration of $0.2 \%(\mathrm{w} / \mathrm{v})$. Four hrs after induction at $37^{\circ} \mathrm{C}, \mathrm{PglB}_{\mathrm{Cj}}$ was re-induced by a second addition of arabinose to maximize glycosylation of AcrA. Cells were harvested by centrifugation after a 20 $\mathrm{h}$ induction period and periplasmic extracts were prepared by lysozyme treatment as described elsewhere [21]. Subsequently, the periplasmic fraction was equilibrated with $1 / 9$ vol $10 \times$ loading buffer $(0.1 \mathrm{M}$ Imidizole, $3 \mathrm{M} \mathrm{NaCl}$, 0.2 M Tris- $\mathrm{HCl} \mathrm{pH} \mathrm{8.0)} \mathrm{and} \mathrm{subjected}$ to a $\mathrm{Ni}^{2+}$ affinity chromatography. The column was equilibrated with 10 column volumes of $1 \times$ loading buffer and loaded on a HisTrap HP column (Amersham Pharmacia Biosciences) at a flow rate of $1 \mathrm{~mL} / \mathrm{min}$. The column was washed with 25 column volumes of wash buffer (0.02 M Imidazole, $0.3 \mathrm{M} \mathrm{NaCl}, 0.02 \mathrm{M}$ Tris- $\mathrm{HCl}$ $\mathrm{pH}$ 8.0), and eluted from the column by elution buffer (0.250 M Imidazole, $0.3 \mathrm{M} \mathrm{NaCl}, 0.02 \mathrm{M}$ Tris- $\mathrm{HCl} \mathrm{pH}$ 8.0).

\section{LPS extraction}

LPS was extracted using the hot phenol-water method as described [35]. The LPS extract was resuspended in 2 $\mathrm{mL}$ of distilled $\mathrm{H}_{2} \mathrm{O}$.

\section{Sugar quantification of glycoproteins}

Protocol was adapted from the total sugar quantification

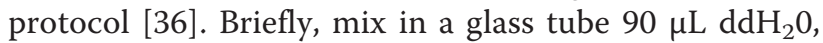
$10 \mu \mathrm{L}$ of sample, and $100 \mu \mathrm{L}$ of $5 \%$ phenol (freshly made) in $\mathrm{dd}_{2} \mathrm{O}$. Briskly add $1 \mathrm{~mL}$ of conc. $\mathrm{H}_{2} \mathrm{SO}_{4}$ into the mixture and immediately vortex the solution for several seconds. An orange color with intensity proportional concentration will begin to develop immediately and reach a maximum after $2 \mathrm{~h} @ 30^{\circ} \mathrm{C}$. Read against chemically synthesized N-formylperosamine standards @ $\mathrm{OD}_{500 \mathrm{~nm}}$.

\section{Western immunoblot}

Western immunoblot was performed based on the procedure described in [37]. Samples were separated on $10 \%$ or $15 \%$ SDS-PAGE gels and transferred to a nitrocellulose membrane via semi-dry membrane transfer and analyzed with a variety of antibodies. $\alpha$-AcrA antibody [38], Yst9-2 antibody [25], and Brucella antibodies M84 [39] were employed as previously described.

\section{Mass Spectrometry}

The nickel column purified protein/glycoprotein was subsequently separated by SDS-PAGE, and the bands corresponding to the desired protein and glycoprotein were in-gel digested with trypsin (Promega) using the protocol of Shevchenko et al. with modification [40]. Briefly, the bands corresponding to the glycoproteins were excised and transferred to $1.5 \mathrm{ml}$ Eppendorf vials. After destaining with $50 \mathrm{mM}$ ammonium bicarbonate in $50 \%$ acetonitrile/water, the gel pieces were dehydrated with acetonitrile and rehydrate with $10 \mu \mathrm{l}$ of $(\sim 2 \mu \mathrm{g})$ trypsin. Then the sample was left in $37^{\circ} \mathrm{C}$ oven for overnight digestion after addition of $50 \mu \mathrm{l}$ ammonium bicarbonate $(50 \mathrm{mM})$ aqueous. The samples were extracted using Zip-Tips (Millipore), and analyzed using a hybrid quadrupole orthogonal acceleration time-of-flight mass spectrometer (Waters, UK) equipped with ananoACQUITY Ultra Performance liquid chromatography system (Waters, Milford, MA). Briefly, $2 \mu$ l of the peptide solution was injected on to a VanGuard micro precolumn C18 cartridge that is connected to a 75 um i.d. $\times$ 150 um Atlantis dC18 column (Waters, Milford, MA). 
Solvent A consisted of $0.1 \%$ formic acid in water, and solvent B consisted of $0.1 \%$ formic acid in acetonitrile. After 1 min trap wash in the precolumn with solvent A at flow rate of $10 \mu \mathrm{l} / \mathrm{min}$, peptides were separated using solvent gradient and electrosprayed to the mass spectrometer at a flow rate of $350 \mathrm{nl} / \mathrm{min}$. The collision energy used to perform MS/MS was varied according to the mass and charge state of the eluting peptides. The instrument is calibrated every $1 \mathrm{~min}$ with GFP and LecErK using the LockSpray. For the data acquisition and analysis, MassLynx (Waters MassLynx V4.1) was used.

\section{Mouse trials experimental design}

A group of $18 \mathrm{BALB} / \mathrm{c}$ female mice were divided into 3 groups and injected intraperitoneally with 1.5 or $3 \mu \mathrm{g}$ of glycosylated AcrA (carbohydrate quantity) or equivalent unglycosylated control in aluminum hydroxide per mouse. The mice were injected with three doses of 2 weeks interval and the challenge was 1 week after the third dose with the virulent $B$. abortus 2308 also via IP. The mice were bled via tail bleed method, resulting in a blood sample of 5-25 $\mu \mathrm{L}$. The blood was allowed to coagulate at $24^{\circ} \mathrm{C}$ for $4 \mathrm{~h}$, after which the samples were centrifuged for $10 \mathrm{~min} @ 13,000 \mathrm{rpm}$ to isolate the blood sera. The sample was stored at $-20^{\circ} \mathrm{C}$ until analyzed. Injections were done according to the TiterMax ${ }^{\circledR}$ Kontes Pellet Pestle ${ }^{\circledR}$ Homogenizer method using TiterMax ${ }^{\circledR}$ Gold. A second bleeding of the mice occurred 6 weeks after the initial injection, resulting in similar sera yields. The mice were given a second injection with the same quantities of sample. The third and final bleed occurred 4 weeks after the second injection, and was also stored @ $-20^{\circ} \mathrm{C}$ until required for analysis.

\section{ELISA analysis of Mouse Sera}

ELISA analysis was done $\left(\right.$ Costar ${ }^{\circledR}$ polystyrene High Binding plate) and optimized from (5). $100 \mu \mathrm{l}$ of each of Y. enterocolitica O:9 (12.5 $\mu \mathrm{g} / \mathrm{mL}$ LPS $)$, Brucella melitensis $(50 \mu \mathrm{g} / \mathrm{mL} \mathrm{LPS})$, and purified AcrA $(1 \mu \mathrm{g} / \mathrm{mL})$ was determined to give the optimal colorimetric response in $0.05 \mathrm{M}$ sodium carbonate buffer ( $\mathrm{pH} 9.8$ ). Wells were blocked using $2.5 \%$ (wt/vol) skim milk in PBS buffer for $1.5 \mathrm{~h}$. Sera from the mice were diluted 1/ 200 in PBS buffer, and $100 \mu \mathrm{L}$ was placed in each well. Plates were washed 3 times with PBST. The $2^{\circ}$ antibodies conjugated to alkaline phosphatase (Biorad Laboratories) were incubated at a dilution of 1:3000 for $1 \mathrm{~h}$ at room temperature. Plates were washed 5 times with PBST, and were incubated with $100 \mu \mathrm{L} p$-nitrophenolphosphate substrate $(1 \mathrm{mg} / \mathrm{mL})$ in $0.05 \mathrm{mM}$ sodium carbonate buffer ( $\mathrm{pH}$ 9.8) for $1 \mathrm{~h} @ 37^{\circ} \mathrm{C}$. Plates were read at $\mathrm{OD}_{405} \mathrm{~nm}$.

\section{Brucella challenge against injected BALB/c mice}

Groups of $6 \mathrm{Balb} / \mathrm{c}$ female mice intraperitonelly vaccinated with either 1.5 or $3 \mu \mathrm{g}$ of the glycoconjugate were challenged 4 weeks after the second dose with $5 \times 10^{4}$ CFUs intraperitoneally of wild type B. abortus 2308 and, 2 weeks post-infection, the bacterial load in the spleens determined as previously described [10].

\section{Magnetic-bead based immunoassays}

Superparamagnectic COOH-modified microbeads (Bangs's Laboratories) were coated with the AcrA-OAg glycoconjugate in one step using EDAC [1-ethyl-3-(3dimethyl-aminopropyl) carbodiimide hydrochloride] and NHS [N-hydroxy succinimide] reactives. Functionalized microbeads were incubated with bovine serum samples (dilution 1/200) and bound antibodies were detected using a Cy5-conjugated goat anti-bovine IgG (Biomeda). Fluorescence reading was performed using a plate fluorometer (DTX 880 Multimode Detector, Beckman Coulter).

\section{Acknowledgements}

We thank Dr. J. A. Bengoechea for kindly providing the strains of $Y$. enterocolitica 0:9 and Dr. D. Bundle for kindly providing N-formylperosamine for quantification of the glycoprotein. This work was supported by grants from Natural Sciences and Engineering Research Council of Canada (NSERC), Alberta Glycomics Centre, the Canada Foundation for Innovation (CFI), the University of Alberta, the Alberta Innovates Technology Futures and Health Solutions, the Alberta Heritage Foundation for Medical Research (AHFMR) to MFF. MFF is an AHFMR scholar and a CIHR New Investigator.

\section{Author details}

${ }^{1}$ Alberta Glycomics Centre, Department of Biological Sciences, University of Alberta, Edmonton, AB, TG6 2E9, Canada. ${ }^{2}$ Alberta Glycomics Centre, Department of Chemistry, University of Alberta, Edmonton, AB, T6G 2G2, Canada. ${ }^{3}$ Department of Medical Microbiology and Immunology, University of Alberta, Edmonton, AB, T6G 2H7, Canada. Instituto de Investigaciones Biotecnológicas, "Dr. Rodolfo A. Ugalde", IIB-INTECH, CONICET, Universidad Nacional de San Martín, Av. Gral. Paz 5445, PREDIO INTI, Edificio 24 (1650), Buenos Aires, Argentina. ${ }^{5}$ Pathogen Molecular Biology Unit, London School of Hygiene \& Tropical Medicine, Keppel Street, London, WC1E 7HT, UK. ${ }^{6}$ GlycoVaxyn AG, Grabenstrasse 3, 8952 Schlieren, Switzerland. 7Department of Biological Sciences, CW 405, Biological Sciences Bldg, University of Alberta, Edmonton, T6G 2E9, Canada.

\section{Authors' contributions}

JAl performed genetic manipulation, protein purification, mass spectrometry analysis, and drafted the manuscript. MAF assisted with mass spectrometry analysis. AF assisted in data interpretation and experimental design. DCM performed initial work and assisted in manuscript editing. MP assisted in experimental design, initial mice testing, and editing the manuscript. CC, AEC, and DJC did experimental work regarding bacterial protection and diagnostic techniques. JEU assisted in designing mice assays, diagnostic experiments and manuscript editing. MFF designed the study, assisted with data interpretation, drafted and edited the manuscript. All authors read and approved the final manuscript.

\section{Competing interests}

A provision patent has been filed regarding the diagnostic application of this technology.

Received: 2 December 2011 Accepted: 25 January 2012 Published: 25 January 2012 


\section{References}

1. Pappas G, Panagopoulou P, Christou L, Akritidis N: Brucella as a biological weapon. Cell Mol Life Sci 2006, 63(19-20):2229-2236.

2. Fugier E, Pappas G, Gorvel JP: Virulence factors in brucellosis: implications for aetiopathogenesis and treatment. Expert Rev Mol Med 2007, 9(35):1-10.

3. Ada G, Isaacs D: Carbohydrate-protein conjugate vaccines. Clin Microbiol Infect 2003, 9(2):79-85.

4. Young EJ, Tarry A, Genta RM, Ayden N, Gotuzzo E: Thrombocytopenic purpura associated with brucellosis: report of 2 cases and literature review. Clin Infect Dis 2000, 31(4):904-909.

5. Corbel MJ: Brucellosis: an overview. Emerg Infect Dis 1997, 3(2):213-221.

6. Franco MP, Mulder M, Gilman RH, Smits HL: Human brucellosis. Lancet Infect Dis 2007, 7(12):775-786

7. Seleem MN, Boyle SM, Sriranganathan N: Brucellosis: a re-emerging zoonosis. Vet Microbiol 2010, 140:(3-4):392-398

8. Pappas G: The changing Brucella ecology: novel reservoirs, new threats. Int J Antimicrob Agents 2010, 36(Suppl 1):S8-11.

9. Schurig GG, Sriranganathan N, Corbel MJ: Brucellosis vaccines: past present and future. Vet Microbiol 2002, 90(1-4):479-496.

10. Ugalde JE, Comerci DJ, Leguizamon MS, Ugalde RA: Evaluation of Brucella abortus phosphoglucomutase (pgm) mutant as a new live roughphenotype vaccine. Infect Immun 2003, 71(11):6264-6269.

11. Jones $C$ : Vaccines based on the cell surface carbohydrates of pathogenic bacteria. An Acad Bras Cienc 2005, 77(2):293-324.

12. Mond JJ, Vos Q, Lees A, Snapper CM: T cell independent antigens. Curr Opin Immunol 1995, 7(3):349-354

13. Astronomo RD, Burton DR: Carbohydrate vaccines: developing sweet solutions to sticky situations? Nat Rev Drug Discov 2010, 9(4):308-324.

14. Meikle PJ, Perry MB, Cherwonogrodzky JW, Bundle DR: Fine structure of A and M antigens from Brucella biovars. Infect Immun 1989, 57(9):2820-2828.

15. Bundle DR, Perry MB: Structure and serology of the Brucella abortus Oantigen. Biochem Soc Trans 1985, 13(6):980-982.

16. Jacques I, Olivier-Bernardin V, Dubray G: Induction of antibody and protective responses in mice by Brucella O-polysaccharide-BSA conjugate. Vaccine 1991, 9(12):896-900.

17. Nothaft H, Szymanski CM: Protein glycosylation in bacteria: sweeter than ever. Nat Rev Microbiol 2010, 8(11):765-778.

18. Faridmoayer A, Fentabil MA, Mills DC, Klassen JS, Feldman MF: Functional characterization of bacterial oligosaccharyltransferases involved in Olinked protein glycosylation. J Bacteriol 2007, 189(22):8088-8098.

19. Kowarik M, Numao S, Feldman MF, Schulz BL, Callewaert N, Kiermaier E, Catrein I, Aebi M: N-linked glycosylation of folded proteins by the bacterial oligosaccharyltransferase. Science 2006, 314(5802):1148-1150.

20. Kelly J, Jarrell H, Millar L, Tessier L, Fiori LM, Lau PC, Allan B, Szymanski CM: Biosynthesis of the $\mathrm{N}$-linked glycan in Campylobacter jejuni and addition onto protein through block transfer. J Bacteriol 2006, 188(7):2427-2434.

21. Feldman MF, Wacker M, Hernandez M, Hitchen PG, Marolda CL, Kowarik M, Morris HR, Dell A, Valvano MA, Aebi M: Engineering N-linked protein glycosylation with diverse $\mathrm{O}$ antigen lipopolysaccharide structures in Escherichia coli. Proc Natl Acad Sci USA 2005, 102(8):3016-3021.

22. Wacker M, Feldman MF, Callewaert N, Kowarik M, Clarke BR, Pohl NL, Hernandez M, Vines ED, Valvano MA, Whitfield C, et al: Substrate specificity of bacterial oligosaccharyltransferase suggests a common transfer mechanism for the bacterial and eukaryotic systems. Proc Natl Acad Sci USA 2006, 103(18):7088-7093.

23. Kowarik M, Young NM, Numao S, Schulz BL, Hug I, Callewaert N, Mills DC, Watson DC, Hernandez M, Kelly JF, et al: Definition of the bacterial Nglycosylation site consensus sequence. EMBO J 2006, 25(9):1957-1966.

24. Bundle DRCJ, Gidney MA, Meikle PJ, Perry MB, Peters T: Definition of Brucella $\mathrm{A}$ and $\mathrm{M}$ epitopes by monoclonal typing reagents and synthetic oligosaccharides. Infect Immun 1989, 57(9):2829-2836.

25. Bundle DR, Gidney MA, Perry MB, Duncan JR, Cherwonogrodzky JW: Serological confirmation of Brucella abortus and Yersinia enterocolitica O:9 O-antigens by monoclonal antibodies. Infect Immun 1984, 46(2):389-393.

26. Skurnik M, Biedzka-Sarek M, Lubeck PS, Blom T, Bengoechea JA, PerezGutierrez C, Ahrens P, Hoorfar J: Characterization and biological role of the O-polysaccharide gene cluster of Yersinia enterocolitica serotype 0:9. J Bacteriol 2007, 189(20):7244-7253.
27. Bundle DR, Cherwonogrodzky JW, Caroff M, Perry MB: The lipopolysaccharides of Brucella abortus and B. melitensis. Ann Inst Pasteur Microbiol 1987, 138(1):92-98.

28. Skurnik M: Lipopolysaccharides of Yersinia Wymondham United Kingdom Horizon Bioscience; 2004

29. Muller-Loennies S, Rund S, Ervela E, Skurnik M, Holst O: The structure of the carbohydrate backbone of the core-lipid A region of the lipopolysaccharide from a clinical isolate of Yersinia enterocolitica 0:9. Eur J Biochem 1999, 261(1):19-24.

30. Ugalde JE, Czibener C, Feldman MF, Ugalde RA: Identification and characterization of the Brucella abortus phosphoglucomutase gene: role of lipopolysaccharide in virulence and intracellular multiplication. Infect Immun 2000, 68(10):5716-5723.

31. Raetz CR, Whitfield C: Lipopolysaccharide endotoxins. Annu Rev Biochem 2002, 71:635-700.

32. Qu H, Xin Y, Dong X, Ma Y: An rmlA gene encoding d-glucose-1phosphate thymidylyltransferase is essential for mycobacterial growth. FEMS Microbiol Lett 2007, 275(2):237-243.

33. Skurnik M, Bengoechea JA: The biosynthesis and biological role of lipopolysaccharide O-antigens of pathogenic Yersiniae. Carbohydr Res 2003, 338(23):2521-2529.

34. Lindberg AA, Haeggman S, Karlson K, Carlsson HE, Mair NS: Enzyme immunoassay of the antibody response to Brucella and Yersinia enterocolitica 09 infections in humans. J Hyg (Lond) 1982, 88(2):295-307.

35. Westphal OJK: Bacterial lipopolysaccharides: extraction with phenol-water and further applications of the procedure. Methods Carbohydr Chem 1965, 5:83-91

36. Dubois MGD, Hamilton JK, Rebers PA, Smith F: Colorimetric method for the determination of sugars and related substances. Anal Chem 1956, 28:350-356.

37. Aebi M, Gassenhuber J, Domdey $\mathrm{H}$, te Heesen S: Cloning and characterization of the ALG3 gene of Saccharomyces cerevisiae. Glycobiology 1996, 6(4):439-444.

38. Wacker M, Linton D, Hitchen PG, Nita-Lazar M, Haslam SM, North SJ, Panico M, Morris HR, Dell A, Wren BW, et al: N-linked glycosylation in Campylobacter jejuni and its functional transfer into E. coli. Science 2002, 298(5599):1790-1793.

39. Nielsen KH, Kelly L, Gall D, Nicoletti P, Kelly W: Improved competitive enzyme immunoassay for the diagnosis of bovine brucellosis. Vet Immunol Immunopathol 1995, 46(3-4):285-291.

40. Shevchenko A, Jensen ON, Podtelejnikov AV, Sagliocco F, Wilm M, Vorm O, Mortensen P, Shevchenko A, Boucherie H, Mann M: Linking genome and proteome by mass spectrometry: large-scale identification of yeast proteins from two dimensional gels. Proc Natl Acad Sci USA 1996, 93(25):14440-14445

doi:10.1186/1475-2859-11-13

Cite this article as: Iwashkiw et al:: Exploiting the Campylobacter jejuni protein glycosylation system for glycoengineering vaccines and diagnostic tools directed against brucellosis. Microbial Cell Factories 2012 $11: 13$.

\section{Submit your next manuscript to BioMed Central and take full advantage of:}

- Convenient online submission

- Thorough peer review

- No space constraints or color figure charges

- Immediate publication on acceptance

- Inclusion in PubMed, CAS, Scopus and Google Scholar

- Research which is freely available for redistribution

Submit your manuscript at www.biomedcentral.com/submit
C Biomed Central 